DE89 002211

\title{
IGNITION AND STEADY-STATE CURRENT DRIVE CAPABILITY OF INTOR PLASMA*
}

\author{
N. A. Uckan \\ Oak Ridge National Laboratory \\ P.O. Box 2009 \\ Oak Ridge, Tennessee 37831-8072 \\ (615) 574-1354
}

\begin{abstract}
The confinement capability of the INTOR plasma for achieving ignition and noninductively driven, $Q>5$ steadystate operation has been assessed for various energy confinement scaling laws and current drive schemes by using a global power balance model. Plasma operation contours are used to illustrate the boundaries of the operating regimes in density-temperature ( $n-T)$ space. Results of the analysis indicate a very restricted capability (if any) for ignition and a limited flexibility in driven modes of operation in the INTOR (8-MA) design. Nearly a factor of two increase in plasma current (through stronger plasma shaping) could improve the feasibility of ignition in INTOR.
\end{abstract}

\section{INTRODUCTION}

A global power balance model has been used to evaluate the confinement capability of the INTOR ${ }^{1}$ plasma. The feasibility for achieving ignition and noninducsively driven, $Q>5$ steady-state operation has been assessed for various confinement scaling laws and current drive schemes. Parameters used are given in Table I. Physics models and assumptions are summarized in Table II.

The confinement assumptions (Table II) are similar to those developed for the Compact Ignition Tokamak (CIT) ${ }^{2}$ and the International Thermonuclear Experimental Reactor (ITER) studies. ${ }^{3}$ For noninductive current drive (CD), results from Fisch, ${ }^{4}$ Ehst, ${ }^{5}$ and the INTOR workshop 6 are used. Details of the global model are given in Ref. 7 . The various terms in the power balance are evaluated assuming renresentative density (a square-root parabolic, $\alpha_{\mathrm{n}}=0.5$ ) and temperature (a parabolic, $\alpha_{T}=1$ ) profiles. The fuel mixture is taken as $50-50$ deuterium-tritium (D-T) plasma with an effective charge $Z_{\text {eff }}=1.5\left[\Delta Z_{\text {eff }}=0.1\right.$ due to thermal alphas $\left(n_{\alpha} / n_{e}=5 \%\right)$ and $\Delta Z_{\text {eff }}=0.4$ due to

\footnotetext{
Research sponsored by the Office of Fusion Energy. U.S. Department of Energy, under contract DE-AC0584OR21400 with Martin Marietta Energy Systems, Inc.
}

Table I. INTOR Machine and Plasma Parameters

Design Parameters [Ref. 3]

\begin{tabular}{ll}
\hline Major radius, $R_{\mathrm{o}}(\mathrm{m})$ & 5.0 \\
Minor radius, $a(\mathrm{~m})$ & 1.2 \\
Elongation, $\kappa$ (at $95 \%$ flux) & 1.6 \\
Triangularity, $\delta$ (at 95\% flux) & 0.25 \\
Toroidal field, $B_{0}(\mathrm{~T})$ & 5.5 \\
Plasma current, $I$ (MA) & 8.0
\end{tabular}

Calculated Parameters

\begin{tabular}{|c|c|}
\hline Aspect ratio, $A=R_{\alpha} / a$ & 4.2 \\
\hline Plasma volume $\left(\mathrm{m}^{3}\right)$ & 227 \\
\hline Plasma surfare area $\left(\mathrm{m}^{2}\right)$ & 328 \\
\hline Wall (chamber) area (m²) & 352 \\
\hline Cylindrical $q .9 *$ (at 95\%) & 1.9 \\
\hline $\begin{array}{l}\text { MHD } q, q_{\Psi} \text { (at } 95 \% \text { ) } \\
\text { Troyon beta limit (\%) }\end{array}$ & 2.2 \\
\hline$\beta_{\text {crit }}=3 l / a B_{0}$ & 3.64 \\
\hline$\left(\beta_{\text {crit }}=4 I / a B_{0}\right.$ & $4.85)^{\circ}$ \\
\hline \multicolumn{2}{|l|}{ Density limit $(1020 \mathrm{~m}-3)$} \\
\hline Murakami-Hugill, $\left\langle n_{\mathrm{mu}}>=1.5 B_{\mathrm{o}} / R_{\mathrm{o}} q^{*}\right.$ & 0.87 \\
\hline Greenwald, $\left\langle n_{\mathrm{gr}}>\approx 0.651 / \pi a^{2}\right.$ & 1.15 \\
\hline$<n\left(\right.$ at $\left.\beta_{\text {total }}=\beta_{\text {crit }}, T=10 \mathrm{keV}\right)>$ & 1.28 \\
\hline (Murakami-like, $<n_{\max }>=1.5 B \alpha R_{0}$ & $1.65)^{0}$ \\
\hline
\end{tabular}

a INTOR assumption (see Ref. 3 ).

carbon and oxygen impurities (with $n_{C} / n_{O}=3$ )]. In addition to the usual conduction and convection losses, only the bremsstrahlung radiation is considered; line radiation and synchrotron radiation are neglected. Plasma operation contours are used to illustrate the boundaries of the operating regimes in density-temperature $(n-T)$ space. The physics requirements and prime operating scenario for (inductively driven) ignited plasmas differ from those of the noninductively driven plasmas, as illustrated in Fig. 1. 
Confinement scalings: $\quad\left(1 / \tau_{E}\right)^{2}=\left(1 / \tau_{E O H}\right)^{2}+\left(1 / \tau_{E a u x}\right)^{2}$ or $\tau_{E}=\min \left[\tau_{E a u x} ; \tau_{E O H}\right]$

with $\tau_{E O H}=\tau_{N A}$ and $\tau_{E \text { aux }}=f \times \tau_{E}($ L-mode $)$ \{or $\tau_{\text {Eaux }}=\tau_{E}(H$-mode $\left.)\right\}$

Neo-Alcator $(\mathrm{OH}) \quad \tau_{\mathrm{NA}}=0.07 n_{20} a R_{0}^{2} q$.

Kaye-Goldston ${ }^{8}(\mathrm{~L}) \tau_{\mathrm{KG}}=0.055 I^{1.24} P-0.58 R_{\mathrm{O}}^{1.65} a^{0.49} \kappa^{0.28} n_{20} 0.26 B^{-0.09}\left(A_{\mathrm{i}} / 1.5\right)^{0.5}$

$\operatorname{ASDEX}^{9}(\mathrm{H}) \quad \tau_{\mathrm{AXH}}=0.1 / R_{\mathrm{O}}$

Goldston ${ }^{10}(\mathrm{~L}) \quad \tau_{\mathrm{G}}=0.037 / P^{-0.5} R_{\mathrm{O}}{ }^{1.75} a^{-0.37} \kappa^{0.5}\left(A_{\mathrm{i}} / 1.5\right)^{0.5}$

$\mathrm{T}-10^{11}(\mathrm{~L})$

$\tau_{\mathrm{T}-10} \approx 0.095 a R_{\mathrm{o}} B \kappa^{0.5} P-(0.4-0.45)\left[Z_{\mathrm{efr}} I^{4} /\left(a R_{\mathrm{o}} a *^{3} \kappa^{1.5}\right)\right]^{(0.08-0.09)}$

Rebut-Lallia ${ }^{12}(\mathrm{~L})$

$\tau_{\mathrm{RL}}=\left[0.024 / l^{1.5} / Z_{\mathrm{eff}} 0.5+0.29 n_{20} 0.75 I^{0.5} B^{0.5} l^{2.75} Z_{\mathrm{eff}}{ }^{0.25} / P\right]\left(A_{\mathrm{i}} / 2\right)^{0.5}$

$J_{A E R I^{13}}(\mathrm{~L})$

$\tau_{\mathrm{J}}=\left[0.085 \kappa a^{2}+0.069 / n_{20}{ }^{0.6} B^{0.2} R_{\mathrm{o}}{ }^{1.6} a^{0.4} \kappa^{0.2} G\left(q *, Z_{\mathrm{eff}}\right) / P\right] A_{\mathrm{i}}{ }^{0.5}$

Kaye-All ${ }^{14}(\mathrm{~L})$

$\tau_{\mathrm{KA}}=0.067 \Gamma^{0.85} P^{-0.5} R_{\mathrm{o}}{ }^{0.85} a^{0.3} \kappa^{0.25} n_{20} 0.1 B^{0.3} A_{\mathrm{i}}{ }^{0.5}$

Kaye-Big $^{14}(\mathrm{~L})$

$\tau_{\mathrm{KB}}=0.105 r^{0.85} P-0.5 R_{0} 0.5 a^{0.8} \kappa^{0.25} n_{20} 0.1 B^{0.3} A_{\mathrm{i}}^{0.5}$

Cument drive: ${ }^{4-6}$

$\gamma_{\mathrm{CD}}=n_{20} I_{\mathrm{CD}} R_{\mathrm{o}} / P_{\mathrm{CD}}=\left(T_{10} / 60\right)[J / P]_{\mathrm{o}}$

with $[J / P]_{0} \Rightarrow$ constant $=10-40 ;$ or $T_{10}[J / P]_{0} \approx$ const $=10-40$

Units/symbols: $2,3,7$

mks, MA, MW, keV, with $\kappa, \delta$ at $95 \%$ flux and

$n_{20}\left(1020 \mathrm{~m}^{-3}\right)$

$=\left\langle n_{\mathrm{e}}\right\rangle / 1020 \mathrm{~m}^{-3}=$ volume-averaged electron density in $10^{20} \mathrm{~m}^{-3}$

$T_{10}(10 \mathrm{keV})$

q*

$=\langle T\rangle / 10 \mathrm{keV}=$ density-weighted average temperature in $10 \mathrm{keV}\left(T_{\mathrm{e}}=T_{\mathrm{i}}=T\right)$

$q_{\psi}$

$f$

$=$ cylindrical equivalent $q$-value $=\left(5 a^{2} B_{\alpha} / R_{\sigma}\right)\left[1+k^{2}\left(1+2 \delta^{2}-1.2 \delta^{3}\right)\right] / 2$

$=$ MHD $q$-value $\approx q * f(\varepsilon)=q *\left[(1.77-0.65 \varepsilon) /\left(1-\varepsilon^{2}\right)^{2}\right] ; \varepsilon=a / R_{0}$

$=\mathrm{L}$-mode enhancement factor (typically, $\mathrm{L}$ mode $f=1 ; \mathrm{H}$ mode $f=2$ )

$A_{\mathrm{i}}$

l(m)

$=$ average atomic mass $=2.5$ for a $50: 50 \mathrm{D}-\mathrm{T}$ plasma

$G\left(q * Z_{\text {eff }}\right)$

$=\left(R_{\mathrm{o}} a^{2} \mathrm{~K}\right)^{1 / 3}=$ characteristic scale length

Zeff

$=Z_{\mathrm{eff}}{ }^{0.4}\left[\left(15-Z_{\mathrm{eff}}\right) / 20\right]^{0.6}\left[3 q_{*}\left(q_{*}+5\right) /\left(q_{*}+2\right)\left(q_{*}+7\right)\right]^{0.6}$

$P(\mathrm{MW})=W / \tau_{\mathrm{E}}$

$=$ effective charge $=1.5$ (assumed for this study)

$[J J P]_{0}$

$I_{\mathrm{CD}}(\mathrm{MA})$

$=0.24 n_{20} T_{10}\left(1+n_{\mathrm{j}} / n_{\mathrm{e}}\right) V / \tau_{\mathrm{E}}=P_{\mathrm{aux}}+P_{\mathrm{OH}}+P_{\alpha}-P_{\mathrm{md}}$

$=$ net "heating" power $=$ [extemal (heating $+C D$ ) + ohmic + alpha - radiation $]$ power

$I_{\mathrm{bs}} / I$

$P_{\mathrm{CD}}(\mathrm{MW})$

$=$ dimensionless current drive efficiency

$=$ driven current $(\mathrm{CD}=\mathrm{LH}, \mathrm{NB}, \ldots)=I-I_{\mathrm{bs}}$

$=$ neoclassical bootstrap current/total plasma current $\propto\left(\varepsilon^{1 / 2} \beta_{p}\right)$

= absorbed current drive power $(\mathrm{CD}=\mathrm{LH}, \mathrm{NB}, \ldots)$

Profiles: $2,3,7$

$n, T \sim\left(1-r^{2} / a^{2}\right)^{\alpha_{n . T}}$ with $\alpha_{\mathrm{n}}=0.5$ and $\alpha_{\mathrm{T}}=1.0$

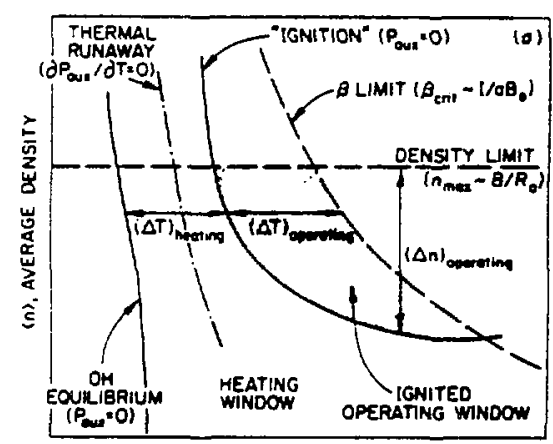

(T), AVERAGE TEMPERATURE

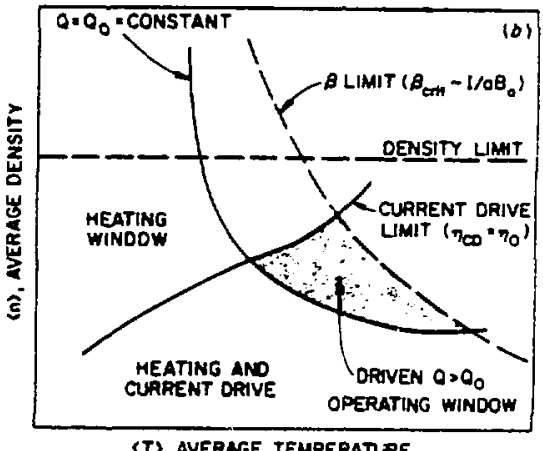

(T). AVERAGE TEMPERATRE

Fig. i. Typical plasma parameter operating space for (a) an ignited and (b) a noninductively-driven system. 
5.:gure 1 shows a typical 'in.ma parameter operating space indicating ignition and a specified $Q=Q_{0}$ contours, along with density and beta limits and a constraint imposed by a given current drive scheme. Subject to the limits (if applicable) and constraints imposed, the shaded regions in the figure correspond to operating windows either for ignition or for $Q \geq Q_{0}$. For the INTOR (8-MA) plasma, results of our analysis presented in the following sections indicate a very restricted capability for ignirion and a limited flexibility in driven modes of operation.

\section{IGNITION CAPABILITY}

The confinement assessments were made for a variety of scalings, ${ }^{8-14}$ although detailed results are presented only for two empirical scaling expressions that were widely used during the INTOR studies. The first is the combined (in a quadratic mean, see Table II) Kaye-Goldston + neo-Alcator (KG+NA) scaling, ${ }^{8}$ in which all heating (including fusion alpha) power is included in the degradation of confinement.

The second is the combined ASDEX- $\mathrm{H}^{9}+$ neo-Alcator (AXH+NA) scaling. In both cases the NA component (i.e., ohmic scaling) sets an upper limit on confinement at low plasma densities. Figure 2 shows the ignition contours for both of these scalings. Contours for the $\mathrm{KG}+\mathrm{NA}$ scaling are for various $\mathrm{KG} \mathrm{L}$-mode enhancement factors (ranging from $1.75 \mathrm{~L}$ to $2 \mathrm{~L}=\mathrm{H}$ ). Also plotted are constant beta contours for the Troyon factor $C=\angle \beta(\%)>/\left(I / a B_{0}\right)=3$ and 4 and the density limits according to the Murakami-Hugill $\left\langle{ }^{\prime} \mathrm{mu}_{\mathrm{m}}\right\rangle$ and the Greenwald $\left\langle n_{\mathrm{gr}}\right\rangle$ scalings (see Table II for corresponding expressions). As a reference, the ignition contour in the limit of NA scaling only is also indicated.

Typically, the NA component does not significantly influence the KG scaling (except for very large $L$-mode enhancement factors). However, the pure ASDEX-H mode scaling is so favorable that it could allow ignition at very low densities, and in such cases the NA limit becomes operative.

As seen from Fig. 2, access for ignition relies on the attainment of some form of an "H-mode." For densities below the Murakami limit ( $\left.<n_{\mathrm{mu}}>-0.9 \times 10^{20} \mathrm{~m}^{-3}\right)$, ignition appears possible only with the ASDEX-H mode. Af higher densities $\left(>1.2 \times 1020 \mathrm{~m}^{-3}\right)$, a small ignition window becomes accessible with the KG H-mode (where $\mathrm{H} \geq 2 \mathrm{~L}$ ). The size of the operating window depends very sensitively on the assumed Troyon beta coefficient and density limit. The INTOR assumption of $C=4$ (with a low edge safety factor of $q_{y}=2.2$ ) is very optimistic (if not unrealistic) from the MHD stability standpoint, and operation with more realistic CIT-like ${ }^{2}(C \leq 3)$ or ITER-like ${ }^{3}(C=2.5$ to 3$)$ assumptions severely restricts (or eliminates) the ignition window. For the assumed density and temperature profiles, ignition in INTOR with a small margin could be possible only at higher density levels with $C>3$ and very favorable ASDEX-H-like scalings. Along the beta contour (3.65\%). the average neutron wall load is $-0.7 \mathrm{MW} / \mathrm{m}^{2}$.

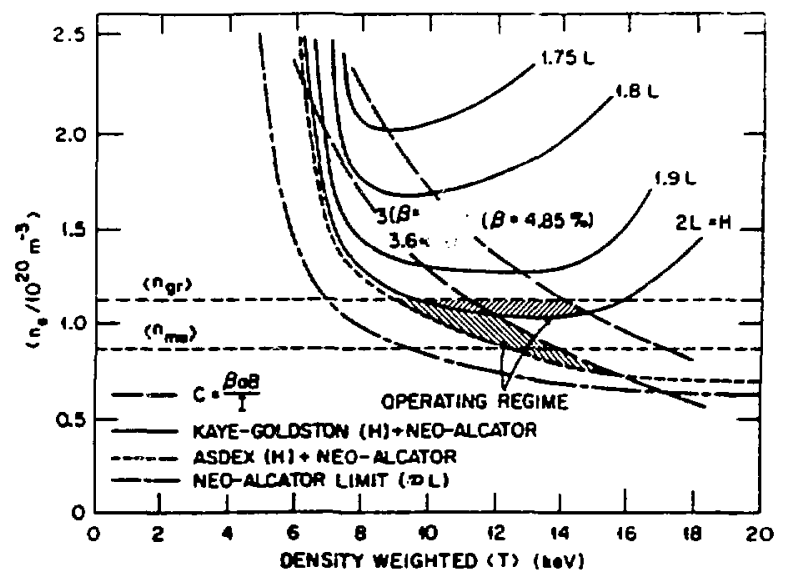

Fig. 2. INTOR ignition contours (solid curves) for various L-mode enhancement factors $(f \sim 1.75$ to 2$)$ of the KayeGoldston L-mode scaling, combined (in inverse quadrature) with the neo-Alcator scaling (KG+NA). Also shown are the ignition capability with a combined ASDEX-H + neo-Alcator (short-dash curve) and the limiting neo-Alcator scaling (long-and-short-dash curve). Beta limits corresponding to the Troyon coefficients $C=3$ and 4 are indicated by longdash curves. Lines marked by $\left\langle n_{\mathrm{mu}}\right\rangle$ and $\left\langle n_{\mathrm{gr}}\right\rangle$ correspond to the Murakami-Hugill and Greenwald density limits. Typical operating windows are indicated by shaded regions.

If the achievable confinement time is below the $\mathrm{H}$ mode enhancement factor of 2 , only subignition operation is possible in INTOR. Results for an enhancement factor of 1.5 of the $\mathrm{KG} \mathrm{L-mode}$ are given in Fig. 3, showing contours of $Q=5$ and 10 and steady-state auxiliary power required $\left(P_{\text {aux }}\right.$ ) to sustain the plasma at a given $\langle n\rangle$ and $<T>$. A small $Q=5$ driven operating window is accessible for $n<n_{\mathrm{mu}}$ and $C \leq 3$ over a temperature range of 8 to $15 \mathrm{keV}$ (see Fig. 2). The required heating power ranges from 20 to $50 \mathrm{MW}$, producing a fusion power ranging from 100 to $250 \mathrm{MW}$ with an average neutron wall load of 0.3 to $0.7 \mathrm{MW} / \mathrm{m}^{2}$. Increase in beta (e.g., $C$ value) does not substantially extend the $Q=5$ operating window for densities $n<n_{\mathrm{mu}}$. For $n=n_{\mathrm{gr}}, Q=7$ at $-10 \mathrm{keV}$. If no density limit is imposed (except the beta limit), a small $Q \sim 10$ operating window becomes accessible around $n \geq$ $1.5 \times 1020 \mathrm{~m}^{-3}$ and $T \sim 7$ to $9 \mathrm{keV}$ with $P_{\mathrm{aux}} \sim 30 \mathrm{MW}$. 


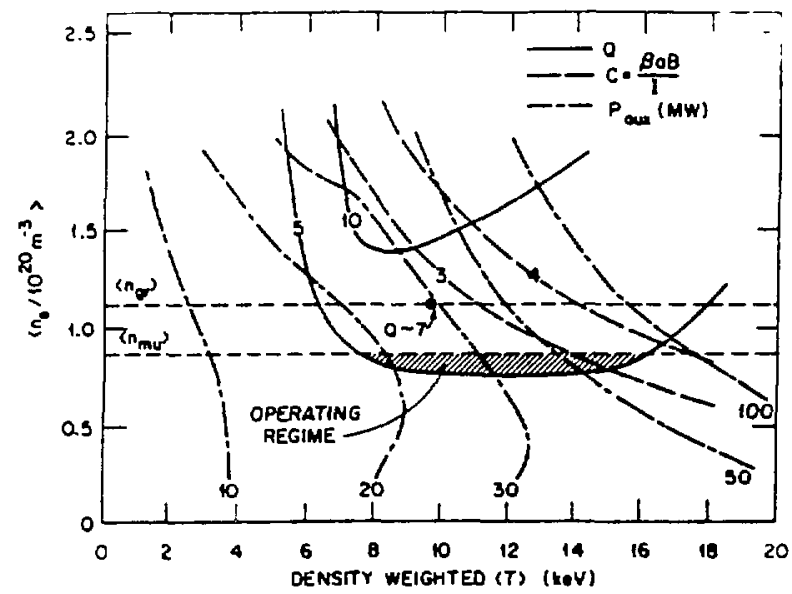

Fig. 3. Steady-state auxiliary power and constant $Q=5$ and 10 contours for inductively maintained INTOR plasma. Confinement model: Kaye-Goldston + neo-Alcator with an L-mode enhancement factor $f=1.5$. A typical operating regime bounded by $Q \geq 5, n \leq n_{m u}$, and $\beta \leq \beta_{\text {crit }}$ is indicated by the shaded region.

The recent assessment of the experimental data base ${ }^{10}$ indicates that both the KG and the AXH scalings are too optimistic. Table III summarizes the INTOR ignition requirements for these and other widely used scaling expessions $8-14$ (see Table II). Given in the table are the minimum L-mode enhancement factors needed for ignition, evaluated at various operational $(n, \beta)$ limits. In nearly all cases (except for ASDEX H-mode), required enhancement factors over L-mode vary from as low as $f \geq 2$ to as high as $f$ i 3 (4 to 6), all of which are well above the enhancement factors observed in the present H-mode experiments (even at low power levels). Nearly a faces of two increase in plasma current (through stronger plasma shaping) could improve the feasibility of ignition in INTOR.

\section{STEADY STATE CURRENT DRIVE CAPABILITY}

To determine the extent of the operaring window in a noninductively driven case, it is necessary to introduce some specific schemes for driving the current. Possible options include high-energy neutral beams (NB), lower hybrid ( $\mathrm{LH}$ ) slow waves, electron cyclotron (EC) waves, and ion cyclotron (IC) fast waves. ${ }^{3-6}$ The neoclassical bootstrap (bs) contribution to the tota' plasma current could also be substantial $\left(I_{\mathrm{bs}} / l \propto \mathrm{E}^{1 / 2} \beta_{\mathrm{p}} \sim 30 \%\right)$. Some of these current drive techniques (NB, EC, IC) are capable of driving the current in the central portion of the plasma, whereas LH waves drive the current in the outer portion of the plasma. Therefore, a combination of techniques $(\mathrm{NB}+\mathrm{LH}+\mathrm{bs}$, $\mathrm{EC}+\mathrm{LH}+\mathrm{bs}, \mathrm{IC}+\mathrm{LH}+\mathrm{bs}$, etc.) may be needed to obtain desired current profiles and current drive efficiencies. In all cases, the current drive figure of merit (global efficiency) is defined as
Table III. INTOR Ignition Capability: L-mode Enhancement Factor ( $f$ ) Needed for Ignition for Various Confinement Scalings [Refs. 8-14]

(Evaluated at Several Operational Limits)

\begin{tabular}{|c|c|c|c|}
\hline \multirow[b]{2}{*}{ Confinement Scaling } & \multicolumn{3}{|c|}{$f($ evaluated at $T \approx 10 \mathrm{keV}$ ) } \\
\hline & $n=n_{\mathrm{mu}}$ & $n=n_{\mathrm{gr}}$ & $\beta=\beta_{\text {crit }}$ \\
\hline $\begin{array}{l}\text { Neo-Alcator (NA) } \\
\text { ASDEX-H (AXH) }\end{array}$ & ～Ignited & Ignited & Ignited \\
\hline $\begin{array}{c}\text { AXH+NA } \\
\text { min[AXH; NA] } \\
\text { Kaye-Goldston (KG) }\end{array}$ & $\begin{array}{l}\text { Not ignited } \\
\text { - Ignited }\end{array}$ & $\begin{array}{l}\text { Ignited } \\
\text { Ignited }\end{array}$ & $\begin{array}{l}\text { Ignited } \\
\text { Ignited }\end{array}$ \\
\hline $\begin{array}{l}\mathrm{KG}+\mathrm{NA} \\
\min [\mathrm{KG} ; \mathrm{NA}]\end{array}$ & $\begin{array}{l}\geqslant 3 \\
\geq 2\end{array}$ & $\begin{array}{l}\geq 2 \\
\geq 1.9\end{array}$ & $\begin{array}{l}\geq 1.9 \\
\geq 1.9\end{array}$ \\
\hline Goldston $(\mathrm{G})$ & & & \\
\hline $\begin{array}{c}\mathrm{G}+\mathrm{NA} \\
\min [\mathrm{G} ; \mathrm{NA}] \\
\mathrm{T}-10(\mathrm{~T}-10)\end{array}$ & $\begin{array}{l}* 3 \\
\geq 2.4\end{array}$ & $\begin{array}{l}\geq 2.6 \\
>2.4\end{array}$ & $\begin{array}{l}\geq 2.5 \\
>2.4\end{array}$ \\
\hline $\begin{array}{l}\min [\mathrm{T}-10 ; \mathrm{NA}] \\
\text { Rebut-Lallia (RL) }\end{array}$ & $\geq 2.2$ & $\geq 2.1$ & $\geq 2.1$ \\
\hline $\begin{array}{l}\min [R L ; N A] \\
\text { JAERI (J) }\end{array}$ & $\sum 2.3$ & $\geq 2.2$ & $\geq 2.1$ \\
\hline $\begin{array}{l}\min [\mathbf{J} ; \mathrm{NA}] \\
\text { Kaye-Al] (KA) }\end{array}$ & $\geq 3.5$ & $\geq 3.4$ & $\geq 3.4$ \\
\hline $\begin{array}{l}\min [\mathrm{KA} ; \mathrm{NA}] \\
\text { Kaye-Big (KB) }\end{array}$ & 23.7 & $\geq 3.6$ & $\geq 3.6$ \\
\hline $\min [\mathrm{KB} ; \mathrm{NA}]$ & $\geq 3.8$ & 23.7 & $\geq 3.7$ \\
\hline
\end{tabular}

$$
\gamma_{\mathrm{CD}}=n_{20} I_{\mathrm{CD}} R_{\mathrm{d}} / P_{\mathrm{CD}}=\left(T_{10} / 60\right)[J / P]_{0}
$$

where (see Table II) $n_{20}=\left\langle n_{\mathrm{e}}\right\rangle / 10^{20} \mathrm{~m}^{-3}$ is the volumeaveraged electron density, $T_{10}=\langle T\rangle / 10 \mathrm{keV}$ is the density-weighted average temperature, $I_{C D}$ is the driven current (MA), $P_{\mathrm{CD}}$ is the (absorbed) current drive power $\left(\mathrm{MW}\right.$ ), and $[J / P]_{0}$ is the dimensionless current drive efficiency. In general, $[J / P]_{0}$ is not constant; it depends on temperature and other physical quantities (such as beam energy and aiming. LH refractive index and accessibility, $T_{c}, Z_{\text {eff }}$, etc.). Typically, ${ }^{4-6} \mathrm{CD}$ efficiencies (for a range of parameters representative of NB, LH, EC, IC, etc.) are $[J / P]_{0}=$ const. $-10-40$ or $T_{10}[J / P]_{0}=$ const. $-10-10$. which yields

$$
\gamma_{\mathrm{CD}}-(0.2-0.6)\left(T_{10}\right)^{x} \text { with } x \sim 0-1 .
$$

Here the range represents "nominal" and "optimistic" levels of the current drive efficiency, which will be used to determine the envelope of the noninductively driven operating regimes in INTOR. 
Results of our analyses for a range of current drive inemes with various efficiencies indicate that a full, $8-11 \mathrm{~A}$ nuninductive current drive capability with a reasonable wili loading is not likely to exist in INTOR. However, it may be possibie to assist the ohmic-inductive capability by using, for example, an $\mathrm{LH}$ wave or an NB to drive some fraction of the plasma current $\left(l_{\mathrm{CD}} / I\right)$. For example, with an L-mode enhancement factor of 2 (KG+NA scaling), a $Q \geq 5$ window with 0.3 to $0.7 \mathrm{MW} / \mathrm{m}^{2}$ of wall loading appears to be accessible for $25-50 \%$ fractional current drive by $\mathrm{LH}$ or NB. A possible bootstrap contribution (up to $30 \%$ ) may improve these fractional limits.

A specific example for $K G+N A$ scaling with an $L$ mode enhancement factor of 1.5 is given in Fig. 4, which shows a $Q=5$ contour and the boundaries of current drive for various schemes with efficiencies $\gamma_{C D}$ ranging from nominal levels, $\gamma_{C D}=0.3$ or $0.3 T_{10}$, to very optimistic levels with substantial bootstrap contribution, $\gamma_{C D}=0.8$ or $0.8 T_{10}$. With nominal $\mathrm{CD}$ efficiencies, only $Q<5$ operation is possible when $\langle T\rangle$ is above 16 to $20 \mathrm{keV}$, $<n\rangle$ is around 0.5 to $0.8 \times 10^{20} \mathrm{~m}^{-3}$, and beta is near that with $C-3$ to 4 , requiring a current drive power of 50 to $100 \mathrm{MW}$. Steady-state operation with $Q \geq 5$ is accessible only if the optimistic levels of $C D$ efficiencies with substantial bootstrap are assumed. In this case, current drive power levels remain below $50 \mathrm{MW}$ with a small operating window (shaded region in Fig. 4) around $\langle\mathrm{T}>-12-15 \mathrm{keV}$, $<\mathrm{n}>\sim 0.8-1 \times 10^{20} \mathrm{~m}^{-3}$.

\section{REFERENCES}

1. See "Intemational Tokamak Reactor Phase Two A, Part II," Intemational Atomic Energy Agency, Vienna (1986); "International Tokamak Reactor Phase Two A, Part III," (to be published).

2. See "CIT Physics Design Description," AE-880112. PPI-01, Princeton Plasma Physics Laboratory (1988); D. POST e: al., "Physics Aspects of the Compact Ignition Tokamak," Phys. Scr., T16, 89 (1987); J. SHEFFIELD et al., "Physics Guidelines for Compact Ignition Tokamak," Fusion Technol., 10, 481 (1986).

3. See "ITER Definition Phase Report," International Atomic Energy Agency, Vienna (to be published); ITER Physics Team (presented by D. POST), "The Physics Basis of ITER," to appear in Proc. 12th int. Conf. Plasma Physics and Controlled Nuclear Fusion Research. Nice, France, October 12-19, 1988; N. A. UCKAN and ITER Physics Team, "ITER Physics Design Guidelines," ITER Repon,International Atomic Energy Agency, Vienna (to be published)

4. N. J. FISCH, "Theory of Current Drive in Plasmas," Rev. Mod. Phys., 59, 175 (1987).

5. D. A. EHST and K. EVANS, Jr., "Multiple Wave Frequency Current Driven Tokamak Reactors in the First Stability Regime," Nucl. Fusion, 27, 1267 (1987).

6. See "Fusion Reactor Critical Issues," LAEA-TEC-DOC441, Intemational Atomic Energy Agency (1987).

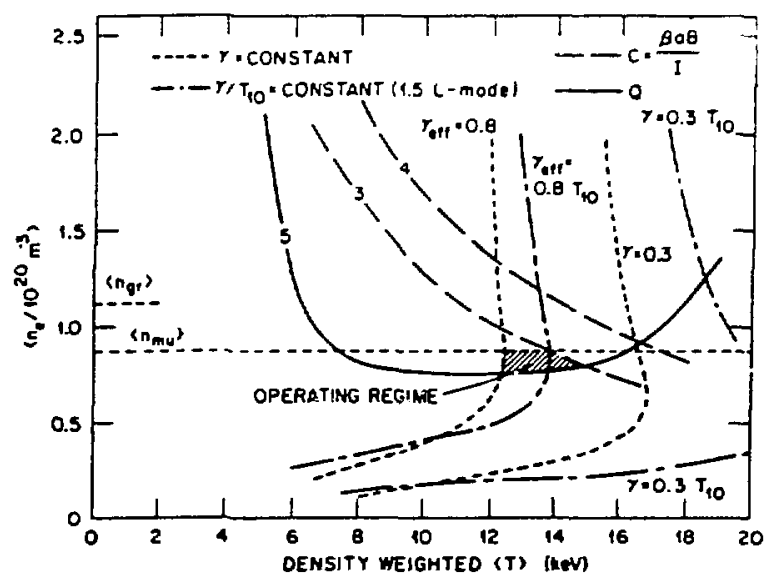

Fig. 4. Boundaries of INTOR steady-state operating space with noninductive current drive. Confinement model: KayeGoldston + neo-Alcator with an L-mode enhancement factor $f=1.5$. Curves representing $C D$ boundaries are for nominal levals with $\gamma=0.3$ and $0.3 T_{10}$ and optimistic levels with $\gamma_{\text {eff }}=0.8$ and $0.8 T_{10}$, which include substantial bootstrap current. These $\mathrm{CD}$ boundaries are the locus of points where the $C D$ power required to drive a specified current ( $8 \mathrm{MA}$ ) equals the auxiliary power needed to satisfy the power balance. Accessible operating regimes (in $n-T$ space) are those on and below the $C D$ boundaries represented by $\gamma$ or $\gamma / T$ contours.

7. N. A. UCKAN, "Relative Merits of Size, Field, and Current on Ignited Tokamak Performance," Fusion Technol., 14, 299 (1988); N. A. UCKAN and J. SHEFFIELD, "A Simple Procedure for Establishing Ignition Conditions in Tokamaks," Tokamak Starrup, p. 45, H. Knoepfel, Ed., Plenum Press, New York (1986).

8. S. M. KAYE and R. J. GOLDSTON, "Globa! Energy Confinement Scaling of Neutral Beam Heated Tokamaks," Nucl. Fusion, 25, 65 (1985).

9. O. GRUBER, "Confinement Regimes in Ohmically and Auxiliary Heated Tokamaks," Proc. Int. Conf. Plosmo Physics, Lausanne, Switzerland, June 27-July 3, 1984, Vol. 1, p. 67, Commission of the European Communities (1984).

10. R. J. GOLDSTON, "Energy Confinement Scaling in Tokamaks," Plasma Phys. Controlled Fusion, 26, 87 (1984).

11. T-10 GROUP (presented by Yu. V. ESIPCHUK), "Investigation of Energy Confinement in ECH Experiments on T-10," and Yu. V. ESIPCHUK "Utilization of ECRH Results from T-10 for Reactor Parameter Prognosis," ITER Specialists' Meeting on Energy Confinement, May 24-27, 1988, Garching, Federal Republıc of Germany (to be published). 
12. P.H. REBUT et al. (presented by P.P. LALLIA), "Critical Electron Temperature Gradient Model," ITER Specialists' Meeting on Energy Confinement, May 24-27, 1988, Garching, Federal Republic of Germany (เo be published); P. P. LALLIA, P. H. REBUT, and M. L. WATKINS, "Chaotic Magnetic Topology and Heat Transport in Tokamaks," JET Report, JET-P(88)05 (January 1988, corrigendum March 1988).

13. K. ODAJIMA and $Y$. SHIMOMURA, "Energy Confinement Scaling Based on Offset Linear Characteristic," JAERI-M 88-068, Japan Atomic Energy Research Institute (March 1988); Y. SHIMOMURA and K. ODAJIMA, "Empirical Scaling of Incremental Energy Confinement Time of L-Mode Plasma and Comments on Improved Confinement in Tokamaks," Comments Plasma Phys. Controlled Fusion, 10, 207 (1987).

14. S. M. KAYE, "Survey of Energy Confinement Scaling Expressions," ITER Specialists' Meeting on Energy Confinement, May 24-27, 1988, Garching, Federal Republic of Germany (to be published).

\section{DISCLAIMER}

This report was prepared as an account of work sponsored by an agency of the United States Government. Neither the United States Government nor any agency thereof, nor any of their emplovees. makes any warranty, express or implied, or assumes any legal hability or responsibility for the accuracy, completeness, or usefulness of any information, apparatus, product. or process disclosed, or represents that its use would not infringe privately owned rights. Refelence herein to any specific commercial product, process, or service by trade name, trademark, manufacturer, or otherwise does not necessarily constitute or imply uts endorsement, recommendation, or favoring by the United States Government or any agency thereof The views and opinions of authors expressed herein do not necessarily state or reflect those of the United States Government or any agency thereof 